\title{
MODELOS DE INVERSIÓN SOCIAL PARA EMPRESAS MINERAS Experiencias y propuestas
}

\author{
Mirella Mogrovejo Álvarez \\ cmogrovejo@xstratacopper.com.pe
}

Renato Pimentel Bernal

renato.pimentel@trafigura.com

Alfredo Zúñiga Huamai

azuniga@xstratacopper.com.pe

\begin{abstract}
Resumen
El auge producido en el país por el incremento de las operaciones y los proyectos mineros ha creado expectativas sobre los beneficios que esta actividad puede generar para las comunidades aledañas a las zonas de operación. Si bien en la mayoría de los casos los resultados no han sido muy alentadores, este trabajo busca demostrar el avance producido en la gestión social de las empresas mineras, sus alcances y propuestas de mejora, a través de la presentación y el análisis comparativo de casos exitosos de modelos de inversión social aplicados en el Perú durante los últimos años. Con este propósito, también desarrolla el tema de los aportes sociales más conocidos en la minería -el canon, las regalías mineras, el aporte voluntario, la contribución social y el fideicomiso social- y explica cómo se ha realizado el proceso de distribución de estos montos.
\end{abstract}

Palabras clave: responsabilidad social, empoderamiento comunitario, buenas prácticas sociales, relaciones comunitarias, inversión social.

\begin{abstract}
Peru is experiencing a boom through growing mine operations and projects. This has created expectations among the benefits that activity may create for the mines' neighboring communities. Although in most cases results have not been very encouraging, this paper seeks to demonstrate whatever progress has been made in the mining companies' social management, and the scope of their proposals for improvement by presenting and comparing successful social investment models used in Peru in recent years. It also examines the issue of the mining industry's voluntary contributions, social contributions and social trust funds, and explains how the money is allocated.
\end{abstract}

Key words: social responsibility, community empowerment, good social practices, community relations, social investment. 


\section{Introducción}

Al investigar el comportamiento de la minería en su dimensión social se encuentran diferentes experiencias y procesos, algunos de ellos exitosos, encaminados a contribuir a generar un escenario de convivencia y comunicación con las comunidades y las poblaciones en sus áreas de influencia.

Allí donde la presencia minera se caracteriza por los buenos resultados económicos provenientes de la explotación de los recursos naturales, también surgen innumerables expectativas de las poblaciones ansiosas por compartir una parte de esa creciente riqueza minera. Por este motivo, desde hace varios años, algunas empresas mineras han emprendido procesos de inversión social encaminados a atender estas expectativas mediante la implementación de interesantes propuestas de construcción de posibilidades de desarrollo sostenible en zonas alejadas de las grandes ciudades y, por tanto, carentes de oportunidades. Algunos de estos procesos se enmarcan en un espacio de relación voluntaria y espontánea y otros, especialmente desde inicios del año 2007, dentro de la legislación que el gobierno ha dispuesto para el sector.

Sin embargo, hasta ahora, el crecimiento de la inversión social de la minería no ha causado un verdadero impacto en las economías de las regiones a las cuales se dirigen los fondos mineros. De allí surge una urgente necesidad de proponer ajustes a los mecanismos de inversión y un mejor impulso de las capacidades de quienes están conduciendo estos procesos.

Este documento analiza la situación en la que se encuentran los aportes provenientes del sector minero, el canon y las regalías, y también los resultados que ha alcanzado la inversión social de las empresas por medio de programas como «Solidaridad con el Pueblo», y otros sistemas como los fideicomisos. A continuación se revisan algunos casos emblemáticos de procesos de gestión de la responsabilidad social, se establece comparaciones entre las buenas prácticas desarrolladas y las lecciones por aprender en este difícil escenario.

\section{El escenario actual del sector minero}

En los últimos años, el país vive una etapa de desarrollo económico impulsado básicamente por el auge de las actividades minero-metalúrgicas y energéticas. Esto se comprueba al observar que la minería ha crecido a una tasa promedio de $8 \%$ y aportado alrededor de $6 \%$ del producto bruto interno (PBI). En la actualidad, las exportaciones mineras representan $60 \%$ de las divisas que ingresan al país y el sector concentra $30 \%$ de la inversión privada directa. Se calcula que sin el impulso de la minería se perdería más de $25 \%$ del producto per cápita y caerían los ingresos tributarios en más de $38 \%$.

En América Latina, el Perú ocupa el segundo lugar en producción de cobre, quinto en el mundo, y el primer lugar en producción de oro y zinc, sexto y tercero en el mundo, respectivamente. Estas cifras evidencian la gravitante participación del sector minero en la economía peruana.

En diferentes regiones se han desarrollado proyectos de exploración y explotación de recursos metálicos y no metálicos administrados por empresas nacionales y extranjeras que, bajo distintos sistemas de gestión, han logrado posicionar a la minería como uno de los sectores más competitivos de la actividad nacional. 
Este auge minero ha generado expectativas por parte del gobierno nacional, los gobiernos regionales y de los otros poderes del Estado. También, desde luego, por parte de las comunidades y las poblaciones afincadas en los entornos de influencia territorial de los proyectos mineros, con lamentables episodios de conflictos y antagonismos que tienen como puntos de divergencia los aspectos ambientales y la necesidad de compartir los beneficios de la explotación minera, más aun en épocas en las cuales los precios internacionales de los metales han incrementado su valor dejando sobreganancias a las empresas.

En el ámbito gubernamental se han promulgado diversas normas como la Ley del Canon Minero y Gasífero y la Ley de Regalías Mineras, enfocadas a gravar las utilidades y las ganancias que genera la minería y captar un porcentaje de estas para el Estado y revertirlo a las zonas de origen del recurso mineral.

Además, a fines del año 2006 se promulgó el Decreto Supremo 071-2006/EM, que creó el Fondo Minero de Solidaridad con el Pueblo, mediante el cual se implementa un aporte voluntario de las empresas mineras equivalente a $3,5 \%$ de sus utilidades anuales después de impuestos, el cual debería ser operado por los gobiernos regionales y locales mediante el establecimiento de programas y proyectos de desarrollo enfocados a atender las principales necesidades de las poblaciones influenciadas por la actividad minera.

El punto de vista de la sociedad civil, especialmente representada por comunidades campesinas, frentes de defensa, organizaciones de base e inclusive alcaldes distritales que residen en las áreas de influencia, es que se hay una gran brecha entre lo que esperan los pueblos del aporte minero y lo que en realidad se ha conseguido de estos fondos invertidos bajo las modalidades descritas.

A este clima se suma, indudablemente, la distorsión del centralismo que convierte a Lima y los poderes del Estado en un factor de freno para el desarrollo de las regiones, a pesar de los importantes montos de financiamiento derivados del auge de la minería y la producción de energía.

También existen otros obstáculos que entorpecen el proceso de impulso a las inversiones sociales procedentes del sector minero, como la limitada capacidad con la que cuentan los gobiernos regionales y locales para disponer y ejecutar los fondos del Foncomún, el aporte voluntario y el Presupuesto Participativo, entre otros.

Asimismo, los gobiernos locales tienen serias dificultades para establecer sus propios equipos de planificación y desarrollo local. Inclusive, muchas autoridades elegidas se encuentran en una total orfandad de asesoría especializada para tomar decisiones en cuanto al uso de los importantes montos que les han transferido desde el Ministerio de Economía y Finanzas. Algunos se apresuran a construir monumentos, plazas o estadios, y otros prefieren guardar los fondos para no incurrir en errores que luego resultan en procesos penales.

Por el lado de las empresas, se detectan dificultades para terminar de entender que, en el escenario actual, la competitividad empresarial ya no se mide solo a través de la producción sino con estándares de comportamiento ambiental y social. Esto último es un tema que requiere maduración en los estamentos de alta dirección de muchas empresas mineras. 
Evidentemente, si no existe un compromiso de responsabilidad social en los niveles ejecutivos resulta más difícil encontrar resultados en los pequeños grupos de operadores de la gestión social que, con activismo, enfrentan los desafíos y, a su vez, tratan de apoyarse en agentes externos como las consultoras y las ONG, que han encontrado un magnífico nicho de mercado en la gestión social.

Otro elemento a considerar es que, a pesar de las positivas cifras que muestra un sector minero en crecimiento y de las oportunidades que se presentan con los programas de inversión en el campo social, la minería no logra todavía liberarse de un cuestionamiento latente: su comportamiento ambiental.

Como se ve, al interior de todos los actores sociales involucrados en esta problemática se encuentran razones para entender por qué la inyección financiera en favor del desarrollo local y regional no ha logrado los frutos buscados ni alcanzado el impacto esperado.

\section{Los aportes de la minería}

A pesar de que el desarrollo económico-social rural no es responsabilidad del sector minero sino del Estado, este puede contribuir sin imposiciones ni sustitución de roles. De hecho, la minería, desde hace varios años, ha generado con sus contribuciones económicas procesos de inversión social, pero estos aún no logran un resultado tangible y menos todavía sostenible.

A continuación se revisan algunos de los principales rubros en los que se ubica el aporte minero, principalmente por la vía de los impuestos, los cuales, por efecto de la legislación actual, se limitan a seguir el procedimiento de pagar al Estado y que reviertan a las zonas de las que provienen bajo diferentes mecanismos y modalidades, no siempre efectivos.

La renta que se genera en el sector minero, y que luego es transferida a las regiones, ha provocado que estas tengan más recursos que nunca, al punto de no saber qué hacer con ellos. Allí es donde radica el riesgo, pues esta etapa de auge minero y grandes oportunidades para el desarrollo descentralizado puede terminar pronto y, con la caída de los precios de los minerales en los próximos años, los proyectos de inversión disminuirán y dejarán nuevamente más frustraciones que satisfacciones.

\subsection{El canon minero}

Según el ordenamiento jurídico peruano, el canon minero es la participación efectiva y adecuada de la que gozan los gobiernos locales (municipalidades provinciales y distritales) y los gobiernos regionales del total de ingresos y rentas obtenidos por el Estado por la explotación económica de los recursos mineros (metálicos y no metálicos). Un porcentaje de los ingresos captados por dicho concepto se transfiere a las zonas en donde se explotó el recurso minero (como se observa en el gráfico 1).

Hasta el año 2006, el canon generado por el pago del impuesto a la renta en un año dado se transfería a los gobiernos regionales y locales a partir de junio del año siguiente hasta mayo del año subsiguiente, distribuido en doce cuotas iguales. A partir del año 2007, la distribución del canon generado en el ejercicio del año 2006 se hace en una sola cuota entregada a los gobiernos regionales y locales a inicios del 


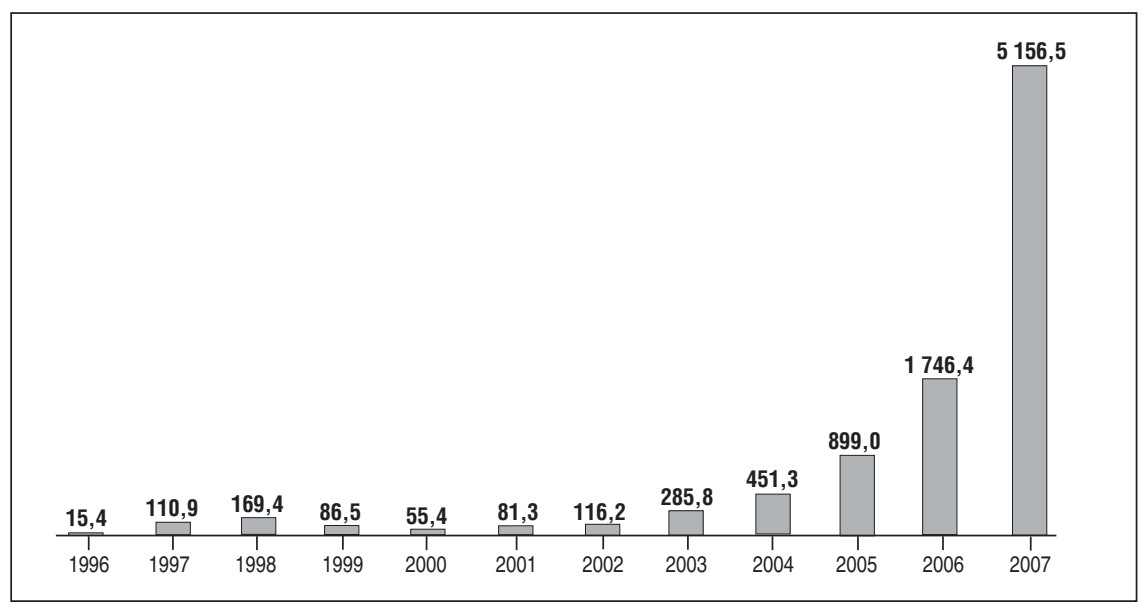

Fuente: Sociedad Nacional de Minería y Petróleo (SNMPE).

\section{Gráfico 1}

Canon minero distribuido, 1996-2007

(millones de soles)

mes de junio. La próxima transferencia de recursos del canon se realizará a mitad del año 2008, con cargo al impuesto a la renta de las empresas mineras por las actividades ejecutadas en el año fiscal 2007. El esquema de distribución del año 2007 se muestra en el gráfico 2.

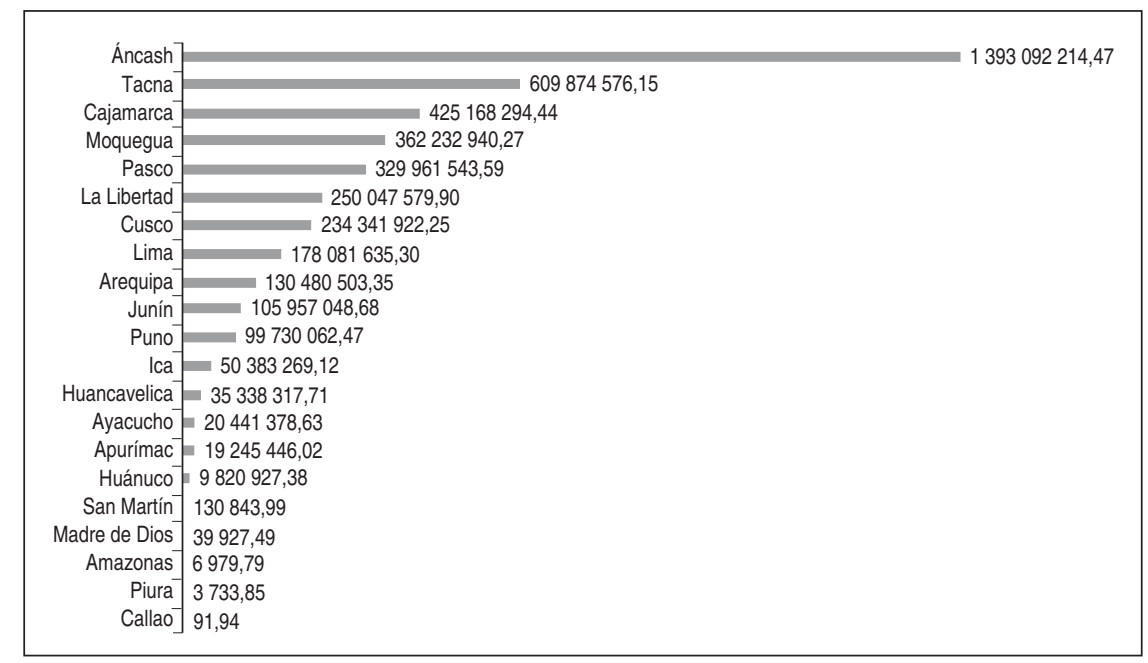

Fuente: SNMPE, 2007.

\section{Gráfico 2}

Distribución del canon minero por regiones, 2007

(millones de soles) 


\subsection{Las regalías mineras}

La regalía minera, creada en junio del año 2004, es una contraprestación económica que los titulares de las concesiones mineras pagan al Estado por la explotación de los recursos minerales metálicos y no metálicos.

El monto recaudado en un mes es distribuido en el mes siguiente a los gobiernos regionales y locales y a las universidades nacionales de las regiones, de acuerdo con el siguiente esquema:

- El 20\% del total recaudado va para los gobiernos locales de la municipalidad o municipalidades distritales donde se encuentran las concesiones mineras en explotación. La mitad de ese monto tendrá que ser invertido en las comunidades donde se explota el yacimiento.
- Otro $20 \%$ va dirigido a los gobiernos locales de la provincia o provincias donde se encuentran las concesiones mineras en explotación.

- Un $40 \%$ va para los gobiernos locales de las circunscripciones departamentales o las regiones donde se encuentren las concesiones mineras en explotación.

- Un $15 \%$ va para los gobiernos regionales donde se encuentran las concesiones mineras en explotación.

- Por último, un 5\% se orienta a las universidades nacionales de la región o las regiones donde se encuentran las concesiones en explotación.

A continuación, el cuadro 1 muestra la distribución de las regalías mineras por regiones.

\section{Cuadro 1. Distribución de las regalías mineras por regiones (nuevos soles)}

\begin{tabular}{l|r|r|r}
\hline \multicolumn{1}{c|}{ Departamento } & \multicolumn{1}{|c|}{$\mathbf{2 0 0 5}$} & \multicolumn{1}{c}{$\mathbf{2 0 0 6}$} & \multicolumn{1}{c}{ Total } \\
\hline Amazonas & 3951 & 1449 & 5400 \\
\hline Áncash & 368680 & 1169660 & 1538340 \\
\hline Apurímac & 1919463 & 1875940 & 3795403 \\
\hline Arequipa & 8029705 & 10811181 & 18840887 \\
\hline Ayacucho & 383993 & 1098214 & 1482208 \\
\hline Cajamarca & 0 & 760210 & 760210 \\
\hline Huancavelica & 2746768 & 3867546 & 6614314 \\
\hline Huánuco & 1261232 & 2328895 & 3590127 \\
\hline Ica & 6155866 & 7621019 & 13776886 \\
\hline Junín & 2417866 & 31315741 & 33733608 \\
\hline La Libertad & 10511465 & 14532489 & 25043954 \\
\hline Lima & 6748569 & 14865852 & 21614421 \\
\hline Moquegua & 72185677 & 100216716 & 172402393 \\
\hline Pasco & 10846780 & 51438799 & 62285579 \\
\hline Piura & 722 & 747 & 1468 \\
\hline Puno & 61703363 & 25683338 & 87386702 \\
\hline San Martín & 20586 & 9854 & 30411 \\
\hline Tacna & 67553475 & 99576050 & 167129525 \\
\hline Total & 255881059 & 367084382 & 620031864 \\
\hline
\end{tabular}

Fuente: Ministerio de Economía y Finanzas (MEF) y Consejo Nacional de Descentralización (CND). 


\subsection{El aporte voluntario}

Desde el año 2006, cuando el precio de los minerales subió considerablemente, el gobierno propuso a las empresas mineras que realizasen un aporte voluntario durante cinco años, como apoyo adicional al Estado en el esfuerzo para luchar contra la pobreza.

Así, en el mes de diciembre de ese año, las empresas mineras privadas y el Estado definieron la estructura de aplicación de este aporte y dieron forma a un convenio modelo, el cual se oficializó mediante los decretos supremos 071-2006/EM y 0332007/EM. Nace de esta manera el Programa Minero de Solidaridad con el Pueblo (PMSP): un aporte de naturaleza voluntaria, extraordinaria y temporal, llamado comúnmente aporte voluntario.

A través de este programa se formaliza el compromiso entre el Estado y las empresas mineras con el objetivo principal de promover el desarrollo social y mejorar las condiciones de vida de las poblaciones ubicadas en las áreas de influencia de las empresas mineras.

El PMSP es un mecanismo que crea un fondo monetario financiado por un aporte voluntario, independiente de las obligaciones tributarias, que realizan las empresas mineras para contribuir con los esfuerzos públicos y privados de lucha contra la pobreza. El total de este aporte durante el año 2007 llegó a los 518 millones de soles.

\subsection{La contribución social}

La contribución social del sector está básicamente representada por los beneficios que reciben los trabajadores, las comuni- dades aledañas, las empresas que trabajan con el sector minero y el país en su conjunto.

No obstante, uno de los principales rubros de contribución social del sector minero está en la generación de empleo en las diversas regiones donde existen proyectos mineros o minas en explotación. Un estudio del Instituto de Ingenieros de Minas del Perú (2007a) reveló que el empleo en la minería para el año 2006 tuvo las siguientes características: 109900 trabajadores directos (5\%), 439600 trabajadores indirectos (20\%) y 1648500 trabajadores en sectores dependientes del minero (75\%), según las estadísticas de empleo del Ministerio de Energía y Minas.

\subsection{El fideicomiso social}

El fideicomiso es otro instrumento utilizado por el sector empresarial y se define como una relación jurídica mediante la cual una persona (fideicomitente) transfiere recursos o bienes a otra persona (fiduciario) que está obligada a utilizarlo en favor del fideicomitente o de un tercero (fideicomisario o beneficiario).

La principal ventaja que ofrece el fideicomiso es la intangibilidad de los recursos, es decir, que estos no pueden ser destinados a otros fines que no hayan sido los previamente establecidos por el beneficiario. Por su parte, el banco fiduciario se encarga de administrar los recursos con el objetivo de que generen la máxima rentabilidad mientras no sean utilizados y lo entrega al beneficiario a medida que este aprueba los proyectos. De esta manera, los pobladores de la zona de influencia, a través de sus autoridades, no tienen que acudir al gobierno regional ni al Ministerio de Economía y Finanzas para solicitar recursos. 


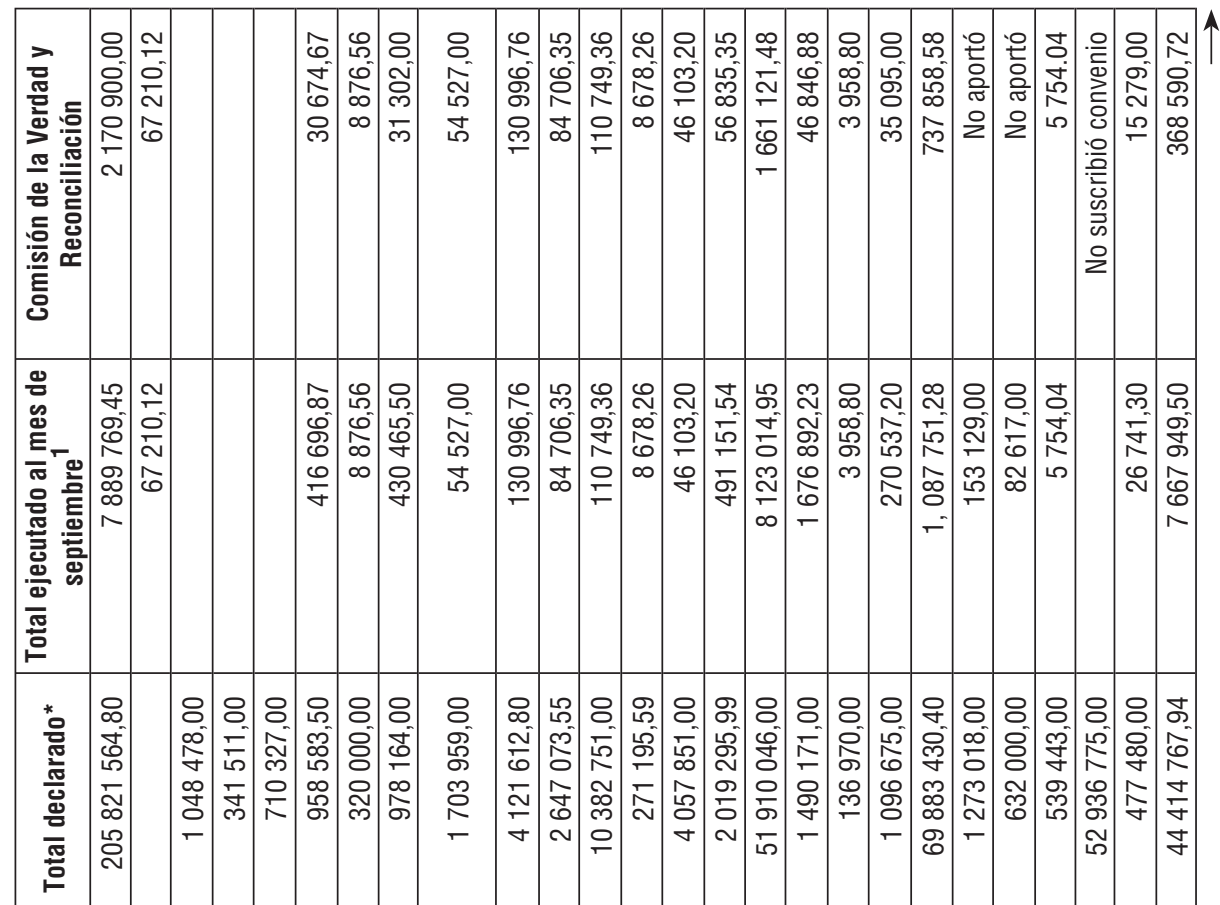

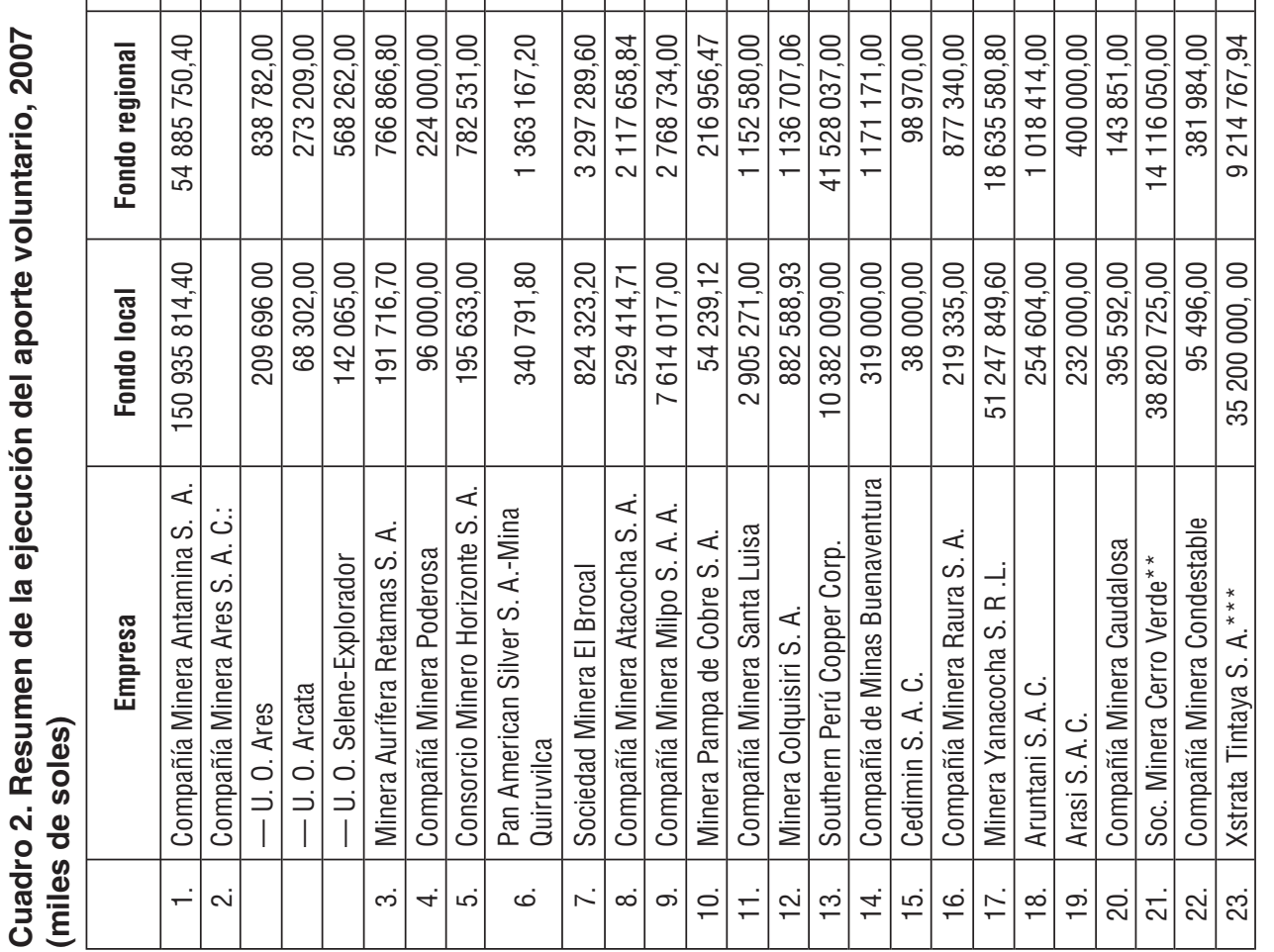




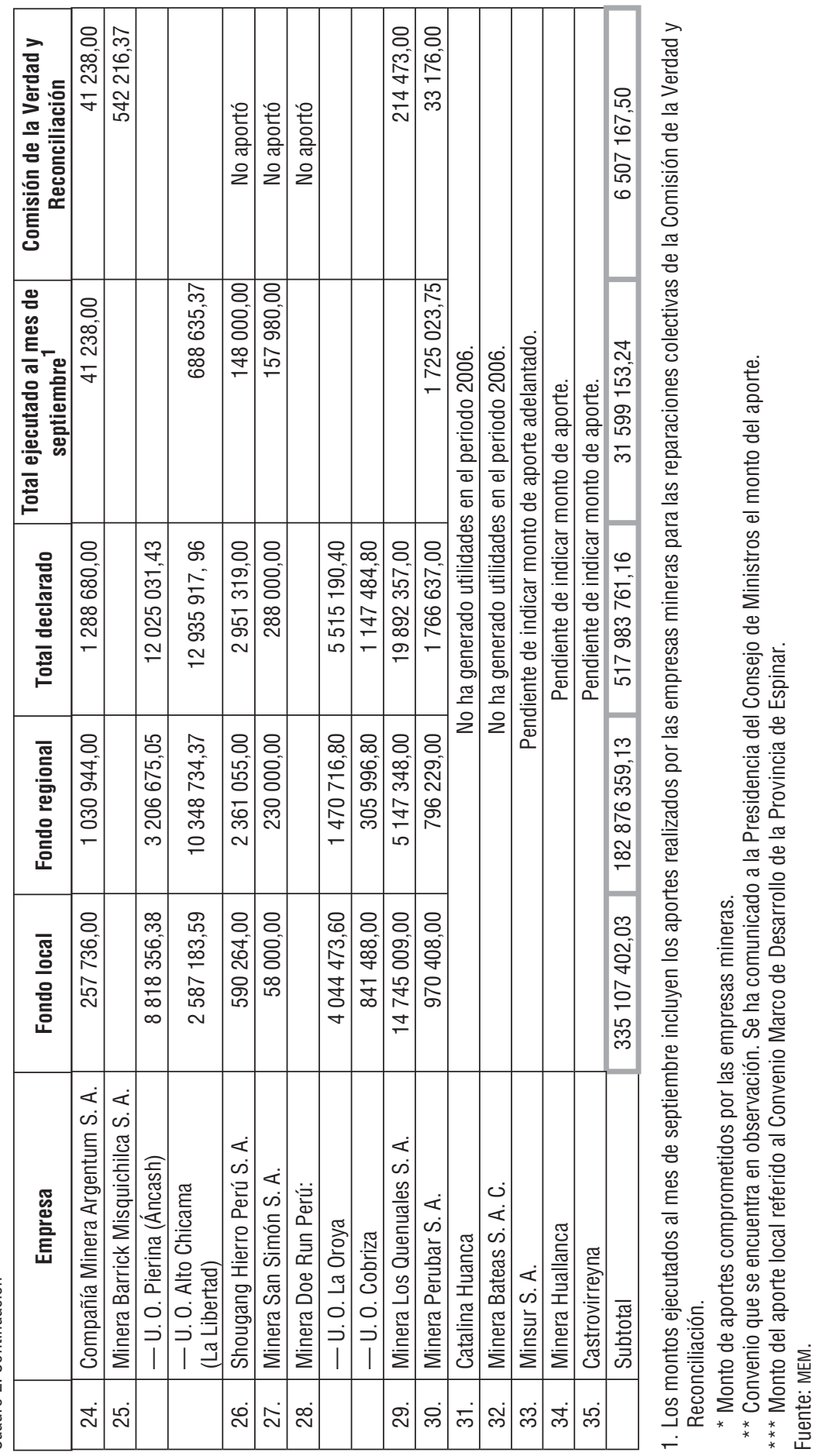


En el Perú, la historia de los fideicomisos sociales es reciente, y estos han estado en manos de Proinversión, entidad del gobierno que ha conseguido privatizar diversos proyectos mineros metálicos y no metálicos incorporando en la fórmula de privatización el componente social en la forma de fideicomiso. No obstante, como en los demás casos, los resultados tampoco son alentadores en términos de ejecución efectiva de los fondos comprometidos por las empresas mineras. El cuadro 3 refleja el estado en el cual se encuentran los principales fideicomisos firmados entre las empresas y el gobierno.

En general, han pasado muchos años desde que las empresas entregaron su primer aporte en favor de las comunidades del entorno. Desde entonces, existen cientos de modelos y formas de beneficiar a los grupos de interés; no obstante, al parecer, ninguno ha encontrado el camino ideal para acabar con los conflictos y lograr el reconocimiento del sector minero como un sector que moviliza la economía del país. En este análisis se revisará algunos casos de empresas que realizan inversión social bajo diversas modalidades, cada una con sus particularidades, aciertos y dificultades propias de la realidad socioeconómica y geográfica a la que pertenece.

\section{Experiencias de gestión social en empresas mineras}

\subsection{Caso Antamina: el Fondo Extraordinario para el Desarrollo Sostenible de Áncash}

La Compañía Minera Antamina vincula firmemente la responsabilidad social al concepto de desarrollo sostenible y su experiencia ya ha madurado y dejado atrás lo que podía ser una política de caridad social o filantropía. Para esta empresa, la gestión social forma parte de la gestión diaria y constituye una variable crítica del negocio, considerando la situación de pobreza en la cual vive la mayoría de las comunidades vecinas a sus operaciones ubicadas en la provincia de Huari (Callejón de Conchucos) en la región Áncash.

Solo en el año 2007, Antamina destinó un presupuesto cercano a los 70 millones de dólares para desarrollar actividades de

\section{Cuadro 3. Estado de la inversión ejecutada en los fideicomisos, diciembre de 2007}

\begin{tabular}{l|l|c|c|c|c}
\hline & \multicolumn{1}{|c|}{ Inicio } & Aporte total* & $\begin{array}{c}\text { Aporte } \\
\text { realizado* }\end{array}$ & $\begin{array}{c}\text { Monto } \\
\text { comprometido }\end{array}$ & $\begin{array}{c}\text { Monto } \\
\text { ejecutado }\end{array}$ \\
\hline Yuncán & Febrero de 2004 & $\begin{array}{c}22,0 \\
17 \text { años }\end{array}$ & 8,2 & $6000000^{* *}$ & 120000 \\
\cline { 2 - 6 } $\begin{array}{l}\text { Las Bambas } \\
\text { Toromocho }\end{array}$ & Octubre de 2004 & $\begin{array}{c}62,0 \\
8 \text { años }\end{array}$ & 46,0 & 41000000 & 11000000 \\
\cline { 2 - 6 } Bayóvar & Noviembre de 2004 & 1,0 & 10,0 & $800000^{* *}$ & Por determinar \\
\cline { 2 - 6 } & Abril de 2005 & 1,0 & 10,0 & 955000 & 132000 \\
\cline { 2 - 6 } Alto Chicama & Septiembre de 2005 & $\begin{array}{c}60,0 \\
10 \text { años }\end{array}$ & 30,7 & 27000000 & 1900000 \\
\cline { 2 - 6 } La Granja & Marzo de 2006 & $\begin{array}{c}11,0 \\
15 \text { años }\end{array}$ & 3,7 & 2100000 & 6800 \\
\hline
\end{tabular}

* Montos en millones de dólares.

** Montos referenciales.

Fuente: Proinversión. 
inversión social. Este fondo es administrado a través de tres plataformas diferentes pero complementarias: Relaciones Comunitarias, Asociación Áncash y Fondo Minero Antamina (FMA).

La plataforma de Relaciones Comunitarias se hace cargo de la construcción y el mantenimiento de buenas relaciones con los vecinos y desarrolla pequeñas obras de infraestructura, atención veterinaria, asesoría técnica a comités ambientales y capacitación; además de un activo programa de contrataciones locales. En palabras de uno de sus principales ejecutivos:

Hoy el $100 \%$ del personal no calificado es contratado de las comunidades circundantes. Nuestro objetivo es ampliarlo al personal calificado, para lo cual trabajamos en fortalecer programas de formación profesional en Áncash.

Nuestras oficinas de Relaciones Comunitarias también desarrollan iniciativas productivas agrícolas y trabajan en la mejora de las redes de agua potable y desagüe (Quijandría, 2007).

Un balance de la inversión realizada por esta área señala que entre 1998 y 2003 se han invertido poco más de 16 millones de dólares, mientras que entre 2004 y 2007 se invirtieron otros 29,8 millones de dólares, es decir, casi 46 millones en total.

Por otro lado, solo en su programa de empleo local, denominado Arukushum, se ha beneficiado a más de cinco mil personas empleándolas en un total de 134 proyectos con una inversión de 2 millones de dólares.

Además, en el año 2006, entre rentas de tercera, cuarta y quinta categoría y otros aranceles, esta empresa ha pagado al Estado peruano 766 mil dólares, equivalentes a 2508453 soles.

La plataforma Asociación Áncash es la fundación corporativa de Antamina, creada el año 2002. Su objetivo es fomentar el desarrollo sostenible en esa región y promover la conservación del patrimonio histórico y cultural. Asimismo, busca generar capacidades para la cogestión de iniciativas en turismo, revaloración de la cultura, manejo de los recursos naturales y aprovechamiento de las ventajas competitivas de la región. Entre los años 2004 y 2005 ejecutó 106 proyectos, por 2385618 dólares, y en el año 2006 tuvo 68 proyectos, por un monto de 1231001 dólares.

Para el año 2007, la asociación financió el monumento arqueológico Chavín de Huántar con 180 mil dólares e impulsó el Corredor de Conservación de Polylepis, en el sur de Conchucos, con 187 mil dólares.

Otros aportes directos de la asociación y de la empresa son el Fondo Inversiones para el Desarrollo de Áncash (2002) por 111,5 millones de dólares, el Fondo Extraordinario Antamina por el Desarrollo Sostenible (FEAD), con proyectos ejecutados previos al pago del canon minero por 2250 millones de dólares y, finalmente, el Fondo de Sostenibilidad para Huarmey, que asciende a un millón de dólares anuales para los años 2006, 2007 y 2008.

En diciembre del año 2006, Antamina se constituyó en la primera empresa del sector en formalizar su aporte individual y voluntario al desarrollo de Áncash. El 1 de mayo de 2007 nació el Fondo Minero Antamina (FMA), un aporte de más de 64,3 millones de dólares, casi el $40 \%$ del total del aporte de todas las empresas mineras en el Perú. 
El FMA comprometió inversiones por 42,7 millones de dólares (66\% del aporte total) para la ejecución de 178 proyectos en sectores como salud y nutrición, educación y desarrollo productivo, entre otros. Informes del Ministerio de Energía y Minas afirman que, a septiembre del año 2007, se había ejecutado 7 millones de soles y, a fines del mismo año, casi $91 \%$ del fondo no estaba en ejecución.

\subsection{Caso Xstrata Tintaya: Convenio Marco por el desarrollo de Espinar}

Xstrata Tintaya es una empresa productora de concentrado y cátodos de cobre ubicada en la provincia de Espinar, Región Cusco, a 4100 m.s.n.m. Desarrolla sus actividades en el Perú sobre la base de los sólidos principios y políticas de la Corporación Xstrata PLC, referidos en especial a proteger la salud y el medio ambiente, garantizar la seguridad de los trabajadores y las poblaciones del área de influencia y realizar un trabajo social responsable con las comunidades.

En este marco, Xstrata Tintaya se ha consolidado como una de las empresas mineras que lidera el trabajo de responsabilidad social en el Perú. Ha centrado sus esfuerzos en crear y establecer instancias

\section{Cuadro 4. Proyectos en desarrollo con el Fondo Minero Antamina (FMA)}

\begin{tabular}{|c|c|}
\hline $\begin{array}{l}\text { Programas en } \\
\text { salud y nutrición }\end{array}$ & $\begin{array}{l}\text { Programa de nutrición con ADRA y Cáritas: } 8 \text { millones de dólares } \\
\text { Mantenimiento de establecimientos de salud (EE. SS.): } 986 \text { mil dólares } \\
\text { Equipamiento de EE. SS.: } 963 \text { mil dólares } \\
\text { Campañas médicas itinerantes focalizadas: } 65 \text { mil dólares } \\
\text { Policlínico móvil en Huarmey: } 224 \text { mil dólares }\end{array}$ \\
\hline $\begin{array}{l}\text { Programas en } \\
\text { educación }\end{array}$ & $\begin{array}{l}\text { Entrega de } 20000 \text { carpetas en toda la región: 1,3 millones de dólares } \\
\text { Refacción de } 300 \text { colegios en 2007: 1,3 millones de dólares } \\
\text { Bibliotecas Fase I: } 181 \text { mil dólares } \\
\text { En revisión: } \\
\text { - Escuelas activas con enfoque intercultural bilingüe } \\
\text { - Becas de pregrado } \\
\text { - Programa de Formación de Maestros } \\
\text { - Implementación de centros de recursos y laboratorios de cómputo }\end{array}$ \\
\hline $\begin{array}{l}\text { Programas } \\
\text { en desarrollo } \\
\text { productivo }\end{array}$ & $\begin{array}{l}\text { Estudio de potencialidades económicas: } 50 \text { mil dólares } \\
\text { Proyecto de mercadeo: } 413 \text { mil dólares } \\
\text { En revisión: } \\
\text { - Fortalecimiento del sector financiero } \\
\text { - Simplificación municipal } \\
\text { - Incubadora de empresas } \\
\text { - Desarrollo productivo para pobladores de bajos ingresos } \\
\text { - Emprendedores sociales }\end{array}$ \\
\hline $\begin{array}{l}\text { Programas de } \\
\text { fortalecimiento } \\
\text { institucional }\end{array}$ & $\begin{array}{l}\text { Unidades de gestión municipal: 1,2 millones de dólares } \\
\text { Proceso de consulta del FMA } \\
\text { En revisión: } \\
\text { - Financiamiento para el estudio de la carretera Huari-Pomabamba-Sihuas }\end{array}$ \\
\hline
\end{tabular}


de diálogo y concertación para promover el desarrollo sostenible de su zona de influencia; como la Mesa de Diálogo establecida con las comunidades ubicadas en el entorno de la operación minera y el Convenio Marco firmado con la provincia de Espinar.

En los últimos cuatro años ha invertido en proyectos de desarrollo sostenible más de un millón de dólares en el marco de esta mesa de diálogo, y ha desarrollado diversos programas destinados a resolver los temas ambientales, de tierras y derechos humanos identificados durante el proceso.

Por otro lado, a través del Convenio Marco, Xstrata Tintaya entrega, desde el año 2003, 3\% de sus utilidades antes de impuestos a la provincia de Espinar, esquema que sirvió de referencia para establecer el actual aporte voluntario del gobierno peruano.

El convenio se rige por sus propios valores y principios, tiene estatutos y reglamentos, además de una estructura que incluye:

- Un Comité de Concertación: con 37 organizaciones participantes en el proceso de elaboración y validación del Convenio Marco. Tiene como órgano principal la Asamblea General.

- Un Comité de Gestión: con ocho integrantes entre los que figuran la $\mathrm{Mu}-$ nicipalidad Provincial, los municipios distritales, el Frente de Defensa, la Federación Campesina, la Asociación de Urbanizaciones, los representantes de las comunidades del entorno de la mina y la representación de Xstrata Tintaya. Este comité tiene un secretario técnico, un equipo técnico y supervisores de programas, todos especializados en desarrollo local.

- Un Comité de Ejecución: está integrado por los beneficiarios, el secretario técnico y los representantes de la entidad ejecutora de cada proyecto. Juntos forman el Comité de Obra.

Sin duda, el impacto económico generado por la inversión de 19 millones de dólares del Convenio Marco a lo largo de sus cuatro años de vigencia ha impulsado visiblemente el desarrollo local y se aprecian tangibles mejoras en los servicios de salud, educación, infraestructura vial, telecomunicaciones y servicios de saneamiento básico y en las actividades agrícolas.

En este último aspecto, la dotación de maquinaria agrícola, sistemas de riego, cabezas de ganado, mejoras en la infraestructura de crianza y el fortalecimiento de las capacidades de los ganaderos y los productores de la zona han impulsado sus actividades habituales, con el consecuente incremento de sus ingresos per cápita.

En cuanto a otros espacios de mejora de oportunidades, el desarrollo de capacidades humanas ha beneficiado hasta ahora a más de 700 pobladores de la localidad, lo que permite avizorar un potencial escenario de creación de nuevos negocios para la zona.

Finalmente, el hecho de desarrollar 260 proyectos de inversión en las comunidades y las localidades de la provincia ha generado un movimiento local de compra de materiales y contratación de servicios que supera el orden de los 4,5 millones de dólares.

Es indudable que esta herramienta de gestión social es la opción con la que cuentan 
los pobladores de Espinar para mantener una relación formal con la empresa minera; mientras que la empresa se beneficia con el consentimiento para operar sus actividades minero-metalúrgicas, dentro de una relación de beneficio mutuo construida con los grupos de interés en procesos en los cuales participan múltiples actores voluntarios.

En el año 2007, en pleno proceso de discusión de la mejora del Convenio Marco, la empresa atravesaba un proceso de administración de sus riesgos y un diario aprendizaje para la mejora continua de su conducta de responsabilidad social.

Además, la iniciativa de establecer un aporte voluntario para el desarrollo del área de influencia directa constituye sin duda una experiencia pionera en el país como intento de una gestión del desarrollo local a partir de la inversión social de la minería. La cual, como se ha señalado, fue el punto de origen de la iniciativa gubernamental hoy denominada Programa de Solidaridad de la Minería, que ya está vigente en todo el país.

\subsection{Caso Buenaventura: Programa de Reducción y Alivio a la Pobreza en Huancavelica (PRA)}

Los PRA son patrocinados por la Agencia de Estados Unidos para el Desarrollo Internacional (USAID). En el Perú se ha implementado varios corredores económicos en diez zonas que están interrelacionadas $\mathrm{y}$ tienen potencial para procesar y ofrecer experiencias de desarrollo e inserción en los mercados, con el consiguiente impacto sobre los ingresos de los pobladores de estas zonas, que por lo general son pobres.

Cuadro 5. Indicadores de resultados del Convenio Marco en Espinar*

\begin{tabular}{l|c|l}
\hline \multicolumn{1}{c|}{ Línea de acción } & \multicolumn{1}{c}{$\begin{array}{c}\text { Beneficiarios } \\
\text { (habitantes) }\end{array}$} & \multicolumn{1}{c}{ Índice de mejora } \\
\hline Desarrollo agropecuario & 34200 & $\begin{array}{l}450 \text { hectáreas } \\
34 \text { tractores } \\
1640 \text { cabezas de ganado }\end{array}$ \\
\hline Salud & 68000 & $\begin{array}{l}\text { Acceso a los servicios básicos de salud en el } \\
\text { Hospital Tipo Il-1 }\end{array}$ \\
\hline Educación & 8000 & $\begin{array}{l}4300 \text { alumnos con mejor infraestructura } \\
29 \text { centros educativos } \\
20 \text { kilómetros de vías } \\
26 \text { comunidades interconectadas por puentes }\end{array}$ \\
\hline Transportes y & 20000 & 2258 familias con energía \\
\hline Energía & 1200 & 3500 familias con servicios \\
\hline Saneamiento básico & 7500 & $\begin{array}{l}\text { Calidad de vida } \\
\text { Acceso a servicios urbanos y rurales }\end{array}$ \\
\hline Infraestructura social & 4000 & $\begin{array}{l}\text { Acceso a la telefonía celular en el distrito capital y } \\
\text { las comunidades cercanas al centro minero }\end{array}$ \\
\hline Telecomunicaciones & 30000 & $\begin{array}{l}\text { Evaluación ambiental de las operaciones de } \\
\text { Tintaya }\end{array}$ \\
\hline
\end{tabular}

*Los indicadores proporcionados por la empresa no muestran una línea de base comparativa.

Fuente: Xstrata Tintaya. 


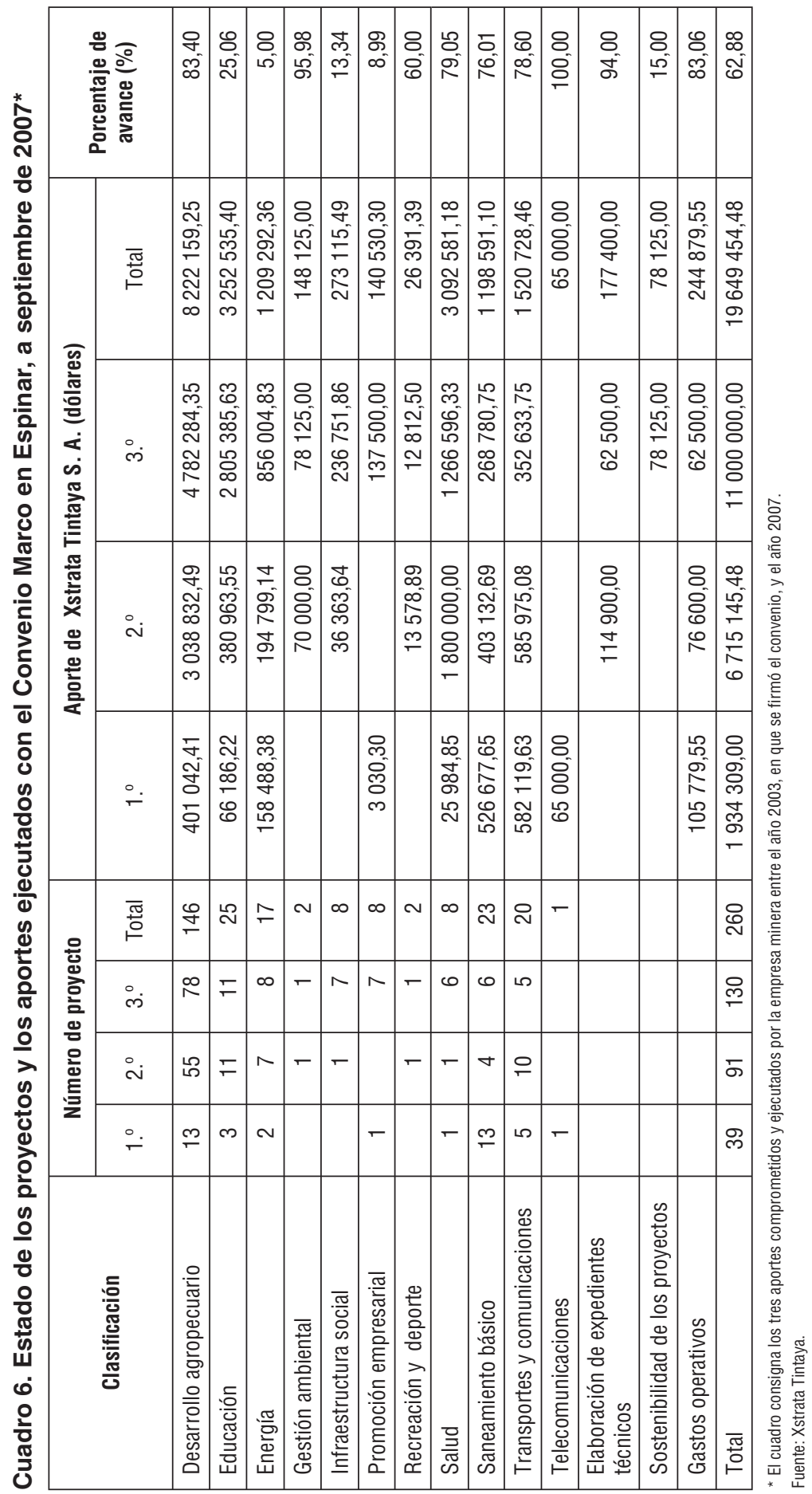


En enero de 2002, la Compañía de Minas Buenaventura se asoció con USAID para financiar un programa en la Región Huancavelica con un fondo total de un millón de dólares para el quinquenio 20022006. Este PRA se propuso crear actividades productivas para incrementar el empleo y los ingresos de las familias huancavelicanas mediante la selección en concursos públicos, con la participación de universidades y gremios empresariales, de proyectos autosostenibles bajo la supervisión de USAID en todas las etapas.

Entre sus avances se puede destacar el fortalecimiento de la capacidad de oferta de los productores de alpaca y vicuña de las comunidades Santa Bárbara, Sacsamarca y Huachocolpa, gracias a la asistencia técnica que permitió mejorar la calidad de la fibra y un mayor valor agregado en el proceso de comercialización; la organización de la cadena productiva de los cultivadores de menestras de Acobamba y Tayacaja, a quienes se les brindó apoyo y asistencia técnica; el reforzamiento de la articulación comercial con los mercados nacional e internacional de los criadores de truchas de Lircay, Choclococha y Acoria; y la organización y asistencia a 280 artesanos productores de artículos decorativos, quienes han logrado vender en Estados Unidos y Canadá a través de diversas empresas exportadoras de artesanías.

Considerando la importancia que tiene para Huancavelica el programa de alivio y reducción de la pobreza, USAID, el gobierno peruano y Buenaventura firmaron, a fines de 2006, un convenio para continuar la ejecución del PRA en Huancavelica con el siguiente esquema de financiamiento: USAID, 30\%; Buenaventura, 40\%; y el gobierno peruano, $30 \%$.

Se espera que los productores locales vendan de manera regular y continua sus productos en los mercados locales y de las grandes ciudades para generar un flujo constante de ingresos y, por consiguiente, mejorar su calidad de vida.

Cuadro 7. Logros del PRA Huancavelica a junio de 2006

\begin{tabular}{c}
\hline Logros del PRA Huancavelica \\
\hline 1248 empleos generados (54\% para mujeres) \\
249501 jornales generados (equivalentes a 200 jornales diarios por \\
cinco años) \\
$2998 \begin{array}{l}\text { productores (familias) articulados a cadenas de negocios } \\
\text { con la ganadería como labor principal }\end{array}$ \\
$7 \begin{array}{l}\text { sectores productivos articulados en los rubros artesanía, } \\
\text { ganadería y agricultura }\end{array}$ \\
$8 \begin{array}{l}\text { productos con mayor volumen de ventas, entre los que } \\
\text { destacan la fibra de alpaca, las alcachofas, la fibra de } \\
\text { vicuña y las truchas }\end{array}$ \\
\hline
\end{tabular}

Fuente: Cía. de Minas Buenaventura, 2006.

Elaboración: IIMP. El informe no muestra línea de base referencial. 


\subsection{Caso Minera Yanacocha: Programa de inversión de la Asociación Los Andes de Cajamarca (ALAC)}

Fundada en marzo de 2004, esta institución de derecho privado es patrocinada por Minera Yanacocha y se dedica a promover programas integrales de desarrollo de las capacidades empresariales e institucionales en Cajamarca. Es el brazo ejecutivo de las acciones de responsabilidad social de la empresa minera y tiene en su equipo profesionales experimentados en temas de desarrollo y sostenibilidad. Por esta razón, se considera un elemento fundamental para operar el aporte voluntario de Yanacocha.

La Asociación Los Andes de Cajamarca (ALAC) ha puesto en los últimos años gran énfasis en promover procesos participativos y desarrollar el capital social y humano en la región Cajamarca; sin embargo, sus programas centrales son el Concurso Anual de Proyectos y el Programa de Desarrollo de Pymes Cajamarquinas.

El concurso anual busca cofinanciar los mejores proyectos de desarrollo de capacidades empresariales e institucionales de Cajamarca. Entre los principales criterios de selección se consideran las estrategias de desarrollo sostenible de la provincia y las capacidades de generación conjunta de sinergias con el sector gubernamental y la sociedad civil.

Mediante convocatorias anuales, ALAC organiza los proyectos que presentan empresas, instituciones estatales y la sociedad civil, entre otras instancias. Un jurado calificador integrado por representantes de instituciones académicas y gremios empresariales se encarga de aprobar las mejores propuestas. Los proyectos que participan deben asegurar un mínimo de $25 \%$ de financiamiento propio y el restante corre por cuenta de otras entidades como Yanacocha, Fondoempleo y la cooperación internacional. Sin embargo, para la ejecución de los proyectos se designa determinadas entidades, privadas o estatales. En todos los casos, ALAC es parte del acompañamiento del proceso.

En cuanto al programa con las pymes, la propuesta de Yanacocha y ALAC es apoyar a los pequeños y los medianos empresarios de Cajamarca con capacitación y asistencia técnica a través de profesionales altamente calificados en las especialidades de desarrollo de productos y articulación comercial. Asimismo, se pone a su disposición un conjunto de servicios financieros con el soporte de la Corporación Financiera Internacional (IFC por sus siglas en inglés).

En sus memorias, ALAC informa que, hasta diciembre de 2006, este programa atendió a 472 empresas y promovió alrededor de 850 puestos de trabajo. También reporta el apoyo a cinco grandes programas de promoción empresarial: Fortalecimiento del Sector Construcción, ejecutado por Cedesco; Fortalecimiento de Proveedores Locales, ejecutado por Recursos S. A. C.; Negocios Artesanales de Cajamarca, ejecutado por Aid to Artisans; Modernización y Diversificación de los Agronegocios en Cajamarca, ejecutado por Technoserve; y Acceso de las Microempresas al Sistema Financiero, ejecutado por el Consorcio Instituto de Formación Bancaria-ONG Colectivo Integral de Desarrollo.

Otra buena práctica de Minera Yanacocha, a pesar de las grandes dificultades en su convivencia con las comunidades que atraviesa en los últimos dos años, es el funcionamiento del centro de innovación tecnológica de joyería Koriwasi, del cual 
ha egresado un buen número de artesanos que trabajan con oro y plata, una legión de nuevos orfebres y artistas que tiene merecido reconocimiento en los mercados de diversos países.

Sin embargo, en el programa del fondo voluntario existe una gran cartera de proyectos por ser ejecutados, pero falta la aprobación del Comité Técnico de Coordinación para invertir estos fondos. Entre estos proyectos figuran la promoción del Circuito Turístico Nor Oriental, el Proyecto de Modernización y Diversificación de los Agronegocios en Cajamarca, el Proyecto de Mejoramiento de la Vivienda y el Desarrollo de Empresas del Sector Construcción, entre otros.

\subsection{Caso Compañía Minera Poderosa: los comités de desarrollo comunal de Pataz, La Libertad}

Bajo el lema «El poder del esfuerzo conjunto», y en asociación con la Municipalidad Distrital de Pataz de la región La Libertad, la Compañía Minera Poderosa ha desarrollado como parte de su enfoque de responsabilidad social un interesante modelo de «empoderamiento comunitario» a través de la integración para el desarrollo de todos los actores sociales: el Estado (gobierno local), la sociedad civil (población) y la empresa privada (Minera Poderosa). Este programa involucra la participación ciudadana como factor clave para asegurar la realización de proyectos de desarrollo sostenible en la zona.

Desde inicios del año 2006, pobladores, autoridades y otros actores sociales clave trabajan en conjunto y asumen la responsabilidad y el compromiso de encaminar el desarrollo de sus propias comunidades bajo un organismo denominado Comité de
Desarrollo Comunal (Codeco) (La Rosa, 2007). De acuerdo con el alcalde de Pataz, Juan Carlos la Rosa, el empoderamiento para generar desarrollo local es un proceso selectivo, consciente e intencionado que tiene como objetivo la igualación de oportunidades entre los actores sociales. En un verdadero proceso de desarrollo local basado en el empoderamiento comunitario, el énfasis está en que el grupo y las personas protagonizan su propio empoderamiento, no se trata de una entidad superior que les da poder.

Los Codeco se constituyen en la organización legítima y representativa de las comunidades. Su principal objetivo es alcanzar el desarrollo de la comunidad a través de la concertación y la integración de todas sus autoridades y representantes de las organizaciones de base existentes en el caserío, así como la articulación de los procesos de salud, educación, económicos y políticos del distrito.

Entre sus principales objetivos se puede citar el propiciar la gobernabilidad del distrito de Pataz mediante el fortalecimiento de su capital humano, social e institucional, de manera que tanto los pobladores como las organizaciones sean gestores de su propio desarrollo; empoderar a los actores sociales clave del distrito de Pataz mediante el desarrollo de nuevas capacidades individuales y colectivas para que aprovechen las oportunidades generadas; facilitar el funcionamiento de mecanismos que aseguren la participación ciudadana, los espacios de concertación y la articulación entre la municipalidad, la empresa privada y la comunidad organizada; integrar a toda la población de la comunidad promoviendo su unidad; concertar en los diferentes espacios y procesos para conseguir su desarrollo; garantizar la transparencia de la gestión 
pública y ser un instrumento de control social; participar en las diferentes instancias de toma de decisiones; y representar y servir como nexo entre la comunidad y las diversas instancias públicas y privadas.

Los resultados obtenidos en Pataz por los Codeco son: la constitución de trece comunidades organizadas y un espacio de concertación llamado Comité Interinstitucional Distrital (CIDDP); la elaboración de trece planes de desarrollo, uno para cada anexo, con la actualización y la articulación del Plan de Desarrollo Distrital con los planes de desarrollo comunal; la realización del Presupuesto Participativo 2007-2008; la firma del I Acuerdo Distrital para la Lucha contra la Pobreza y la Búsqueda del Desarrollo Humano Sostenible de Pataz; y el cumplimiento al ciento por ciento de las obras aprobadas en el Presupuesto Participativo del año 2006. En el gráfico 3 se presenta el organigrama de un Codeco.
También se ha logrado una mejora de las relaciones de confianza entre el gobierno local, la comunidad y la empresa; el funcionamiento de un buen gobierno local en la Municipalidad de Pataz y de la política de responsabilidad social por parte de Minera Poderosa; y el impulso y el reconocimiento de la relación entre la municipalidad, el CIDDP y la empresa como organizaciones promotoras del desarrollo local del distrito.

Respecto de los proyectos gestionados y aprobados por los Codeco en el tema de salud pública, se ha buscado una mayor valoración por parte de los pobladores y las autoridades de la salud y el saneamiento. En cuanto a la educación social, los proyectos se han dirigido a la internalización del enfoque de desarrollo humano sostenible por parte de las autoridades comunales y municipales y a lograr un proceso de concientización del enfoque

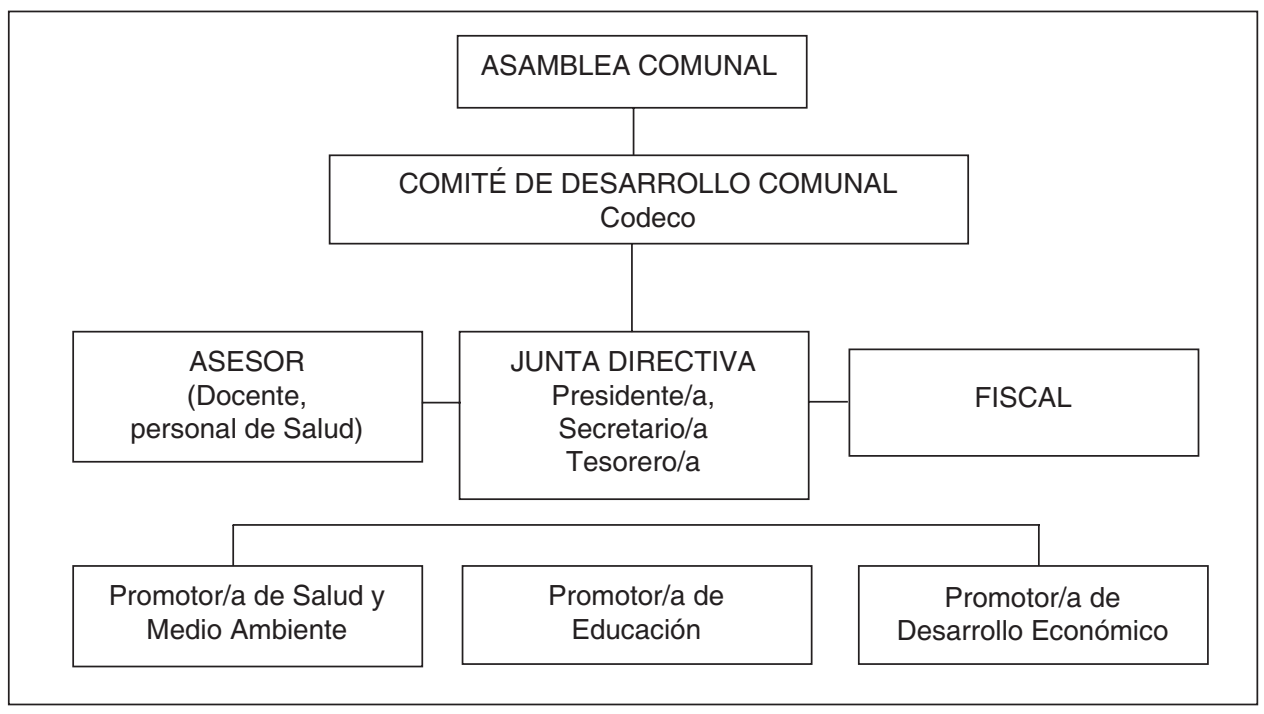

Fuente: La Rosa, 2007.

Gráfico 3

Organigrama de un Codeco 
de responsabilidad social en los trabajadores de la empresa. Sobre los proyectos de desarrollo económico, se ha logrado la participación de $43 \%$ de las comunidades en el I Concurso de Proyectos Productivos y se ha conseguido la administración y la vigilancia de los recursos públicos por parte de los Codeco.

\subsection{Caso Cormin Callao: un modelo de responsabilidad social}

El análisis de las buenas prácticas sociales realizadas por Cormin Callao permite afirmar que la empresa operadora de los depósitos de concentrado en el terminal portuario del Callao ha establecido una positiva conducta de responsabilidad social empresarial (RSE) externa. Así, ha logrado una sólida relación con la población urbanomarginal que se encuentra asentada en los alrededores del depósito de concentrados y también con las principales instituciones públicas y privadas que tienen presencia en el área de influencia directa e indirecta de sus operaciones.

En términos del perfil de RSE externa recomendado en los estándares internacionales, se observa que Cormin Callao ha realizado acciones y conseguido importantes logros en la mayoría de temas clave. Sus acciones han ido más allá de lo que señalan las leyes nacionales para las operaciones de depósitos de concentrados.

Ante la delicada situación ambiental que enfrentan las operaciones de los depósitos de minerales en el Callao, Cormin asumió su responsabilidad con acciones específicas destinadas a atender los casos críticos de concentraciones de plomo detectadas en la sangre de las personas, sobre todo en niños. Estas medidas superan las ordenanzas de la Municipalidad Provincial del Callao.
También ha realizado mejoras sustanciales en los procedimientos de manipulación y almacenamiento de concentrados, en comparación con lo realizado por el anterior operador del depósito. Para ello ha construido nueva infraestructura y adquirido maquinaria y equipos de alto rendimiento. La percepción de que la empresa ha realizado esfuerzos importantes por reducir la contaminación ambiental es generalizada entre los propios trabajadores del depósito y los pobladores de los asentamientos vecinos.

La política de empleo de la empresa ha permitido generar puestos de trabajo para muchas familias que viven en las áreas de influencia directa e indirecta de las operaciones. En este contexto, ha contratado a pobladores de los asentamientos vecinos, quienes han tenido la oportunidad de desarrollar sus capacidades en labores de limpieza, jardinería y seguridad.

En cuanto a la salud y la educación de los pobladores, la empresa ha realizado acciones de apoyo sostenido a centros de salud e instituciones educativas. También ha colaborado con la mejora de la infraestructura, el equipamiento y la limpieza de los comedores populares y las organizaciones del Vaso de Leche.

La empresa también ha sostenido una fluida comunicación con actores clave de la comunidad, a través de los cuales puede estar al tanto de los problemas de los vecinos y recibir propuestas para impulsar proyectos de ayuda social.

Un aspecto relevante de la buena relación comunitaria de Cormin Callao es la sensibilidad y la acertada visión social que ha tenido respecto de la población vecina. La empresa ha identificado aspectos 
medulares de la identidad cultural local y hacia ellos ha dirigido acciones concretas de apoyo y así ha conseguido un impacto positivo en la opinión pública.

También ha llevado adelante una política de formación de alianzas estratégicas con instituciones públicas y privadas que tienen presencia en la zona. Ha impulsado proyectos con la Dirección de Salud del Callao, la Universidad Cayetano Heredia, la ONG Vida y el programa A Trabajar Urbano. La empresa tiene una importante participación en el Grupo Técnico para la Prevención, Reducción, Control y Contaminación por Plomo en El Callao, instancia consultiva del gobierno regional en la materia.

\section{Análisis comparativo de los sistemas de gestión de la responsabilidad social y la inversión social de los casos identificados: las buenas prácticas}

En el país funcionan 47 empresas en la gran y la mediana minería y, junto a ellas, cerca de 30 empresas de exploración y otras 28 de pequeña minería, y es muy complejo establecer un rango de cumplimiento de estándares de responsabilidad social para todas ellas.

Determinar qué modelos son los más adecuados y que prácticas deben estandarizarse resultaría una tarea difícil dado el inmenso y variado contexto sociopolítico, económico y geográfico en el que cada una de ellas se desenvuelve. Sin embargo, a partir de los casos analizados se puede ensayar un análisis comparativo que permita determinar las ventajas, las desventajas, los logros y los alcances y, a partir de este, empezar a delinear una «hoja de ruta» para el sector minero que sea respaldada por las organizaciones y las entidades de la sociedad civil y refrendada por el gobierno mediante sus organismos competentes.

Se deben destacar los modelos de las empresas que han formado sus propias fundaciones o asociaciones privadas como órganos alternos al área que opera las relaciones comunitarias dentro de la organización. Este modelo es una réplica del que se sigue en Chile y Colombia, donde existen fundaciones corporativas con medio siglo de vida y un futuro asegurado por los aportes de la cooperación internacional, más allá de la duración de las operaciones o inversiones mineras que les dieron vida.

En el caso peruano, las fundaciones o las asociaciones cubren el espacio especializado de atención de los procesos de desarrollo local en las zonas donde operan las mineras. Con equipos especializados, un régimen legal más independiente y la opción de ser perceptores de donaciones, pueden hacer que la inversión social minera alcance mejores resultados en un menor tiempo y, sobre todo, consiguen la fidelización de la marca de la empresa que financia estos procesos.

Otra de las prácticas destacables son los programas o los proyectos encaminados al empoderamiento comunitario o a fortalecer el capital social. Esto porque se reconoce que, sin un adecuado compromiso por parte de los actores involucrados en el desarrollo, la sostenibilidad será solo un mito para quienes pretendan alcanzarla.

El empoderamiento de autoridades, líderes comunales y otros miembros de la sociedad civil es un logro que ha permitido, en algunos casos, promover verdaderos procesos de concertación y construcción de consensos, con los cuales fue posible 
asumir los acuerdos y los compromisos necesarios para llevar adelante proyectos y realizar inversiones. No hay una modalidad específica de empoderamiento o concertación, pero sí se reconoce que es muy necesario promover la institucionalidad, la fortaleza de autoridades y organizaciones para entender y enfrentar sus propios procesos de desarrollo. Muchos alcaldes no tienen la formación ni la preparación adecuadas para efectuar inversión social o construir desarrollo local, pero pueden ser formados y capacitados para este reto, junto con otros actores de la sociedad civil. Con personas capacitadas y comprometidas es más viable emprender procesos de construcción del desarrollo sostenible.

En este punto se puede citar también otra buena práctica encontrada de manera constante en el estudio de los casos referidos, se trata de las políticas y los objetivos de responsabilidad social y/o relaciones con las comunidades que deben estar plenamente identificados, declarados, validados y respaldados por las organizaciones. En casi todos los casos se ha encontrado que las políticas existen y los objetivos sociales están incluidos en la planificación estratégica de las empresas; no obstante, se necesita cristalizar estos postulados mediante mecanismos apropiados y adaptados a cada realidad. Por tanto, más allá de lo que significa tener políticas y objetivos en el tema social, hay que vivir esas políticas y trabajar por esos objetivos. Por lo general, las empresas forman equipos reducidos de especialistas que de inmediato buscan asesoría externa y respaldo de otros equipos ajenos a la empresa.

Lamentablemente, esto no es lo más conveniente porque lo que se deduce de los casos revisados es que para la empresa el considerar el tema social es tan crítico como lo son la seguridad, la salud ocupacional, la protección ambiental o el clima organizacional. Estos temas no deberían ser encargados a agentes externos que no tienen un compromiso real con la organización más allá del interés o la relación de negocio que se establece.

Se ha identificado que los equipos que tienen a los especialistas «dentro» brindan mejores respuestas a los problemas sociales al demostrar compromiso e identificación con la organización pues, en buena cuenta, son el rostro de la empresa cuando se trata de entablar una relación con los grupos de interés clave. Por esto, la conclusión es que en los casos analizados es una constante que los equipos de Relaciones Comunitarias sean cada vez más sólidos, organizados y articulados directamente con la línea de mando de la empresa, es decir, son un valor muy importante en la estrategia misma del negocio como órgano de línea y no solo de soporte.

Empresas como Antamina, Xstrata Tintaya, Southern Peru y Buenaventura, entre otras, tienen sus propias gerencias de Relaciones Comunitarias, donde se analizan los aspectos clave de este tema en nexo directo con la unidad ejecutiva más alta: Gerencia General.

En cuanto a la ejecución de las iniciativas de inversión social, la investigación realizada a estas empresas indica que solo algunas tienen un verdadero control sobre los proyectos que se realizan. En varios casos, la intervención de autoridades, ONG y los propios organismos del Estado hacen que estos proyectos caminen a la velocidad del Sistema Nacional de Inversión Pública (SNIP), con el consiguiente perjuicio para el que financia el fondo y para los beneficiarios del proyecto. 
Las empresas que mejor control tienen sobre la fase de ejecución de los proyectos aprobados o priorizados por las comunidades son las que mejores resultados obtienen respecto del reconocimiento de las comunidades sobre el valor de la inversión social minera. Muchos son los casos en los cuales fondos millonarios como los provenientes del canon o las regalías se encuentran sin ser ejecutados en el corto o el mediano plazo, precisamente por falta de mecanismos adecuados de control o viabilidad de los proyectos.

Si bien es cierto que fondos como los del canon o las regalías son de entera responsabilidad de los gobiernos locales y regionales, existen otros fondos como el aporte voluntario que, sin llegar a menoscabar el espíritu del Decreto Supremo 0712006/EM, pueden ser utilizados con mayor actitud emprendedora por las empresas para cristalizar el anhelo de las comunidades de compartir los beneficios procedentes de la minería.

En este escenario existen diversas modalidades para obtener un mejor control de los fondos en la etapa de socialización de los proyectos $\mathrm{y}$, sobre todo, en su fase de ejecución.

Otra etapa que requiere mucho control es la medición, la evaluación y el seguimiento de los proyectos y los procesos de inversión social. De hecho, un análisis de los casos revisados da cuenta de que la mayoría de empresas tiene un sistema de medición de esos impactos, pero en fase de implementación. En otras experiencias, son las ONG asociadas las que miden estos impactos o resultados de los proyectos; o los equipos de Relaciones Comunitarias se limitan a trabajar con indicadores generales como el número de proyectos ejecutados frente al número de proyectos comprometidos, o reportan datos como el porcentaje de ejecución del presupuesto asignado para un proyecto $\mathrm{A}$ o $\mathrm{B}$.

Sin embargo, el manejo de estos indicadores no es suficiente para verificar el verdadero impacto que tienen las inversiones sociales producidas por la minería en un determinado contexto local. En este sentido, faltan las herramientas y los mecanismos que con el transcurrir de los procesos formarán parte de la gestión de la nueva generación de gerentes de desarrollo social que tiene en sus manos este desafío.

Una de las conclusiones del análisis de los casos descritos conduce a la siguiente afirmación: ningún modelo de gestión social o inversión en desarrollo podrá ser exitoso si no se ve fortalecido con un sistema de comunicación basado en estrategias para las diferentes etapas y los distintos procesos: socialización, empoderamiento, priorización de proyectos, ejecución de estos y reporte de resultados. En palabras del ingeniero Lucio Ríos Quinteros, presidente del Instituto de Seguridad Minera (ISEM): «Hay que hacer lo que se dice, y luego hay que decir lo que se hace» (2007).

Este sistema de comunicación no se refiere solo a publicaciones o reportes anuales de sostenibilidad, como en la mayoría de las empresas analizadas, sino a un sistema de interrelación con la comunidad interna y externa de la empresa; es decir, un sistema que mantenga vigente lo que la empresa construye en términos de desarrollo para su sostenibilidad y la de las comunidades involucradas. Es fundamental que este sistema cuente con herramientas de retroalimentación e involucre criterios de diversidad intercultural. 


\section{Cuadro 8. Cuadro comparativo de gestión e inversión de empresas que operan con responsabilidad social}

\begin{tabular}{|c|c|c|c|c|c|}
\hline & $\begin{array}{l}\text { Política de } \\
\text { RSE }\end{array}$ & Objetivos & $\begin{array}{l}\text { Programas } \\
\text { de inversión } \\
\text { social }\end{array}$ & $\begin{array}{c}\text { Participación de } \\
\text { otros actores } \\
\text { (mecanismos de } \\
\text { participación social } \\
\text { y apoyo) }\end{array}$ & $\begin{array}{l}\text { Alineamiento con } \\
\text { los dispositivos del } \\
\text { gobierno }\end{array}$ \\
\hline $\begin{array}{l}\text { ANTAMINA } \\
\text { Asociación } \\
\text { Áncash } \\
\text { Fondo Minero } \\
\text { Antamina }\end{array}$ & $\begin{array}{l}\text { Tiene una política } \\
\text { declarada y } \\
\text { aprobada por sus } \\
\text { accionistas. }\end{array}$ & $\begin{array}{l}\text { Buenas } \\
\text { relaciones con } \\
\text { sus vecinos } \\
\text { e impulso al } \\
\text { desarrollo } \\
\text { de la región } \\
\text { Áncash. }\end{array}$ & $\begin{array}{c}\text { Programas } \\
\text { de Relaciones } \\
\text { Comunitarias, } \\
\text { Asociación } \\
\text { Áncash y } \\
\text { Fondo Minero } \\
\text { regional y } \\
\text { local. }\end{array}$ & $\begin{array}{c}\text { Emplea a la } \\
\text { Asociación Áncash } \\
\text { como aliado para } \\
\text { ejecutar proyectos. }\end{array}$ & $\begin{array}{l}\text { Aplica lineamientos } \\
\text { del DS-071-2006. }\end{array}$ \\
\hline $\begin{array}{l}\text { XSTRATA } \\
\text { TINTAYA } \\
\text { Convenio Marco }\end{array}$ & $\begin{array}{c}\text { Tiene una política } \\
\text { declarada e } \\
\text { implementada. }\end{array}$ & $\begin{array}{l}\text { Sostenibilidad } \\
\text { para la } \\
\text { operación } \\
\text { minera y la } \\
\text { comunidad } \\
\text { del área de } \\
\text { influencia. }\end{array}$ & $\begin{array}{l}\text { Mesa de } \\
\text { Diálogo. } \\
\text { Convenio } \\
\text { Marco. } \\
\text { Fundación } \\
\text { Tintaya. } \\
\text { Fondo } \\
\text { Regional. }\end{array}$ & $\begin{array}{l}\text { Participa con } \\
\text { ONG, autoridades } \\
\text { regionales, } \\
\text { provinciales, } \\
\text { distritales y } \\
\text { comunales. } \\
\text { Involucra a su } \\
\text { Fundación Tintaya } \\
\text { en la ejecución de } \\
\text { proyectos. }\end{array}$ & $\begin{array}{l}\text { Sus mecanismos } \\
\text { de inversión fueron } \\
\text { muy anteriores a los } \\
\text { de los dispositivos } \\
\text { del gobierno. } \\
\text { En parte no } \\
\text { se encuentran } \\
\text { alineados con los } \\
\text { detalles del DS.071- } \\
2006 \text {. }\end{array}$ \\
\hline $\begin{array}{l}\text { BUENAVENTURA } \\
\text { Programa de } \\
\text { Reducción y Alivio } \\
\text { de la Pobreza en } \\
\text { Huancavelica }\end{array}$ & $\begin{array}{c}\text { Tiene una } \\
\text { declaración de } \\
\text { RSE. }\end{array}$ & $\begin{array}{l}\text { Se enfoca } \\
\text { a promover } \\
\text { capacidades } \\
\text { en su área de } \\
\text { influencia. }\end{array}$ & $\begin{array}{c}\text { PRA } \\
\text { Huancavelica. } \\
\text { Fondo Minero } \\
\text { Regional. }\end{array}$ & $\begin{array}{l}\text { USAID, gobierno } \\
\text { central, ONG y } \\
\text { gobiernos locales. }\end{array}$ & $\begin{array}{l}\text { Aplica lineamientos } \\
\text { del DS-071-2006. }\end{array}$ \\
\hline $\begin{array}{l}\text { YANACOCHA } \\
\text { Asociación } \\
\text { Los Andes de } \\
\text { Cajamarca }\end{array}$ & $\begin{array}{c}\text { Tiene una política } \\
\text { declarada. }\end{array}$ & $\begin{array}{l}\text { Promoción de } \\
\text { capacidades } \\
\text { en Cajamarca. }\end{array}$ & $\begin{array}{l}\text { ALAC. } \\
\text { Fondo } \\
\text { Regional. }\end{array}$ & $\begin{array}{l}\text { Gobiernos locales, } \\
\text { ONG, cooperación } \\
\text { internacional. }\end{array}$ & $\begin{array}{l}\text { Aplica lineamientos } \\
\text { del DS-071-2006. }\end{array}$ \\
\hline $\begin{array}{l}\text { PODEROSA } \\
\text { Comités de } \\
\text { desarrollo } \\
\text { comunal de Pataz }\end{array}$ & $\begin{array}{l}\text { Existe una } \\
\text { declaración. }\end{array}$ & $\begin{array}{l}\text { Empoderamien- } \\
\text { to comunal para } \\
\text { el desarrollo. }\end{array}$ & $\begin{array}{l}\text { Codeco. } \\
\text { Fondo local. }\end{array}$ & $\begin{array}{l}\text { Autoridades, } \\
\text { organizaciones, } \\
\text { sociedad civil, } \\
\text { ONG. }\end{array}$ & $\begin{array}{l}\text { Aplica acuerdos con } \\
\text { la Municipalidad de } \\
\text { Pataz. }\end{array}$ \\
\hline CORMIN CALLAO & $\begin{array}{l}\text { Está en } \\
\text { elaboración. }\end{array}$ & $\begin{array}{l}\text { Buenas } \\
\text { relaciones con } \\
\text { el distrito y los } \\
\text { asentamiento } \\
\text { humanos. }\end{array}$ & $\begin{array}{l}\text { Prevención y } \\
\text { control de la } \\
\text { salud de niños. } \\
\text { Apoyo a la } \\
\text { educación. }\end{array}$ & $\begin{array}{l}\text { Trabaja con los } \\
\text { gobiernos central y } \\
\text { local y organismos } \\
\text { de base. }\end{array}$ & $\begin{array}{l}\text { Aplica dispositivos } \\
\text { de la Municipalidad } \\
\text { Provincial del Callao y } \\
\text { el MEM. }\end{array}$ \\
\hline
\end{tabular}




\begin{tabular}{|c|c|c|c|c|c|}
\hline $\begin{array}{l}\text { Efectividad en } \\
\text { la ejecución } \\
\text { de los } \\
\text { proyectos }\end{array}$ & $\begin{array}{l}\text { Control de los } \\
\text { fondos }\end{array}$ & $\begin{array}{l}\text { Sistema de } \\
\text { medición y } \\
\text { control }\end{array}$ & $\begin{array}{c}\text { Estrategia } \\
\text { de } \\
\text { comunicación }\end{array}$ & $\begin{array}{l}\text { Nivel de } \\
\text { reconocimiento } \\
\text { de las } \\
\text { comunidades }\end{array}$ & $\begin{array}{c}\text { Evaluación y control } \\
\text { de riesgos }\end{array}$ \\
\hline $\begin{array}{l}\text { No logra } \\
\text { un nivel de } \\
\text { ejecución } \\
\text { óptimo por } \\
\text { intervención } \\
\text { de actores } \\
\text { politizados. }\end{array}$ & $\begin{array}{l}\text { Lo comparte } \\
\text { con otros } \\
\text { actores. }\end{array}$ & $\begin{array}{l}\text { Se encuentra en } \\
\text { implementación } \\
\text { con apoyo } \\
\text { externo. }\end{array}$ & $\begin{array}{l}\text { Es buena para } \\
\text { el público } \\
\text { nacional y } \\
\text { regional. }\end{array}$ & $\begin{array}{l}\text { Es bueno en el } \\
\text { nivel nacional, no } \\
\text { en la región. } \\
\text { En el nivel local } \\
\text { es variable en } \\
\text { cada área de } \\
\text { influencia. }\end{array}$ & $\begin{array}{l}\text { No tiene } \\
\text { implementado aún } \\
\text { un sistema. }\end{array}$ \\
\hline $\begin{array}{l}\text { Tiene un } \\
\text { avance de } \\
67 \% \text { en } \\
\text { proyectos. } \\
\text { Cuenta con } \\
\text { la Fundación } \\
\text { Tintaya como } \\
\text { principal } \\
\text { entidad } \\
\text { ejecutora. }\end{array}$ & $\begin{array}{l}\text { Controla el } \\
100 \% \text { de } \\
\text { sus fondos } \\
\text { de inversión } \\
\text { social. No } \\
\text { entrega dinero } \\
\text { a gobiernos } \\
\text { locales. }\end{array}$ & $\begin{array}{c}\text { Utiliza el } \\
\text { Balance Score } \\
\text { Card, todavía } \\
\text { en fase de } \\
\text { consolidación. }\end{array}$ & $\begin{array}{c}\text { Se enfoca } \\
\text { principalmente } \\
\text { en el público } \\
\text { local y menos } \\
\text { en el regional. } \\
\text { Bajo perfil } \\
\text { en el nivel } \\
\text { nacional. }\end{array}$ & $\begin{array}{c}\text { En el plano } \\
\text { local es alto y } \\
\text { regular en el nivel } \\
\text { regional. } \\
\text { En el nivel } \\
\text { nacional el } \\
\text { desempeño social } \\
\text { de la empresa no } \\
\text { es relevante. }\end{array}$ & $\begin{array}{c}\text { Tiene en } \\
\text { construcción } \\
\text { un sistema de } \\
\text { gestión del riesgo } \\
\text { sociopolítico. }\end{array}$ \\
\hline $\begin{array}{l}\text { Ha logrado } \\
\text { avanzar con } \\
\text { grupos de } \\
\text { pequeños } \\
\text { empresarios. }\end{array}$ & $\begin{array}{l}\text { No los maneja } \\
\text { directamente. }\end{array}$ & $\begin{array}{c}\text { Tiene un sistema } \\
\text { asociado con el } \\
\text { PRA. }\end{array}$ & $\begin{array}{l}\text { Está enfocada } \\
\text { en sus áreas } \\
\text { de influencia } \\
\text { directa. }\end{array}$ & $\begin{array}{l}\text { Solo en la zona } \\
\text { de impacto } \\
\text { directo. }\end{array}$ & $\begin{array}{c}\text { Está en } \\
\text { construcción. }\end{array}$ \\
\hline $\begin{array}{l}\text { Comité Local. } \\
\text { No logra } \\
\text { avanzar en } \\
\text { proyectos } \\
\text { estratégicos. }\end{array}$ & $\begin{array}{l}\text { No los dispone } \\
\text { directamente. }\end{array}$ & $\begin{array}{c}\text { Tiene } \\
\text { indicadores que } \\
\text { mide ALAC. }\end{array}$ & $\begin{array}{l}\text { Es bueno en } \\
\text { los niveles } \\
\text { regional y } \\
\text { nacional. }\end{array}$ & $\begin{array}{l}\text { No logra aún el } \\
\text { reconocimiento } \\
\text { esperado en los } \\
\text { niveles local y } \\
\text { regional. }\end{array}$ & $\begin{array}{c}\text { Está en } \\
\text { implementación. }\end{array}$ \\
\hline $\begin{array}{l}\text { Efectivo para la } \\
\text { identificación y } \\
\text { la aprobación. }\end{array}$ & $\begin{array}{l}\text { Los manejan los } \\
\text { Codeco y no la } \\
\text { empresa. }\end{array}$ & $\begin{array}{c}\text { En } \\
\text { implementación. }\end{array}$ & Limitado. & $\begin{array}{l}\text { Es bueno por } \\
\text { el nivel de } \\
\text { concertación } \\
\text { alcanzado. }\end{array}$ & No está elaborado. \\
\hline $\begin{array}{l}\text { Mediano } \\
\text { avance, pocos } \\
\text { proyectos en } \\
\text { agenda. }\end{array}$ & $\begin{array}{l}\text { Los maneja } \\
\text { directamente. }\end{array}$ & En elaboración. & $\begin{array}{c}\text { En } \\
\text { implementación. }\end{array}$ & $\begin{array}{l}\text { Es alto en el plano } \\
\text { local, mediano en } \\
\text { el regional. }\end{array}$ & $\begin{array}{l}\text { En proceso de } \\
\text { implementación. }\end{array}$ \\
\hline
\end{tabular}


Aunque en la mayoría de casos analizados se encuentran resultados efectivos y muy buenas iniciativas para el desempeño social en la minería actual, siempre quedan campos que se pueden mejorar. Uno de estos es el de la administración de los riesgos sociales y políticos a los que se enfrentan en general todas las actividades mineras en el país.

Más allá de la legitimidad de la oposición a la actividad minera y de las actitudes antimineras, y por encima de los elementos en debate sobre las cuestiones ambientales, las empresas encuentran un verdadero talón de Aquiles en sus estrategias de manejo del riesgo social y político. A partir del análisis de las empresas consideradas en este artículo, no se encuentran sistemas estructurados para la administración de estos riesgos, en parte porque las empresas no comunican este tipo de prácticas y porque todavía estos temas son manejados en las áreas de Seguridad, las cuales por lo general marchan paralelas a lo que hacen y piensan las áreas de Relaciones Comunitarias.

No se puede negar que existen algunas prácticas en desarrollo para gestionar los riesgos provenientes del contexto local $\mathrm{y}$, con estas prácticas, un conjunto de estrategias, alguna más efectiva que otra, enfocadas en la búsqueda de monitorear los entornos, identificar sus grupos de interés, inclusive buscar controlar posibles peligros que pudieran dañar el propósito y la imagen empresarial.

Este es un terreno mucho más delicado que el monitoreo de medios o el análisis de grupos de interés en la matriz de poder e influencia. En este delicado campo, las empresas todavía no pueden desplegar sus herramientas pues se enfrentan al peligro de atravesar la delgada línea de la intromisión en los asuntos políticos de determinada localidad.

Legítimo o no, estar atento o convivir con lo que ocurre en el escenario político local no significa necesariamente convertirse en un actor político más de una localidad con opinión, decisión y ejercicio del poder. Allí está el límite de la delgada línea que recomienda no estar ni tan lejos ni tan cerca de estos complicados escenarios donde confluyen intereses y posiciones muy diversos, entre los que podemos citar a actores sociales como los partidos políticos, las ONG, algunos sectores de la Iglesia y los medios de comunicación, entre otros.

\section{Conclusiones y recomendaciones}

El desarrollo económico-social del país no es responsabilidad del sector minero sino del Estado; sin embargo, debido a su crecimiento, la minería puede contribuir a hacer realidad verdaderos procesos de construcción de un desarrollo sostenible en las zonas donde operan las empresas de este sector. Con este propósito, requieren adoptar una conducta de responsabilidad social guiada por la concertación con otros actores sociales que reconozcan el aporte y la importancia del sector minero como agente promotor del desarrollo para reducir la pobreza en las regiones y los pueblos alejados de los grandes centros del poder económico.

Los procesos de inversión social que a lo largo de los años ha realizado la minería han permitido gestar experiencias de desarrollo local y regional, las cuales han madurado en forma aislada y con resultados focalizados en sus lugares de origen, de allí que la población en su conjunto aún no percibe en su total dimensión el verdadero 
impacto en favor del país que tienen estas inversiones. Asimismo, estos procesos de inversión social todavía atraviesan un camino lleno de dificultades generadas por factores legales, metodológicos, institucionales y técnicos que limitan igualmente el logro de los objetivos planteados en su concepción.

El papel que le compete al Estado está centrado en la tarea de legislar, pero en la realidad no alcanza resultados por una falta de institucionalidad de los órganos descentralizados que lo representan. Como consecuencia de ello, ingentes cantidades de dinero están en las arcas municipales y regionales a la espera de una «luz verde» que les permita utilizarse en proyectos de desarrollo. Además, la velocidad de ejecución en la administración pública está muy por debajo de las expectativas de la población de ver obras realizadas. Este es el caso de los fondos del canon y las regalías fruto de la actividad minera.

Contando con una legislación y una promoción adecuadas, la inversión social del sector minero debe tener como prioridad y meta asegurar la sostenibilidad del desarrollo nacional y especialmente del área rural. Debe centrar su rol en estrategias que fomenten su desarrollo sostenible con una conducta de responsabilidad social y ambiental que trascienda los esfuerzos alcanzados hasta el momento, a partir de un proceso de redimensionamiento de su competitividad en el campo social, con modelos e ideas innovadoras y alentando a las autoridades y la sociedad civil a integrarse en esta tarea de luchar contra la pobreza y construir en forma estratégica la sostenibilidad de las áreas de influencia minera.

El problema de la insatisfacción social frente a la minería no está en los grandes o insuficientes aportes que efectúen las empresas mineras. La contribución económica y social del sector ha crecido, pero sus resultados no reflejan esta tendencia. Se necesita que el impacto de los recursos sea rápido, eficiente, participativo, rentable económica y socialmente, generador de empleo y mayores ingresos, y represente una mejora tangible en el nivel de vida de la población rural. Para ello se requiere el concurso de todos los actores, cada uno cumpliendo su papel: Estado, empresas y sociedad civil, asumiendo compromisos serios y urgentes que permitan aprovechar los precios altos y las sobreganancias mineras.

Es posible que con el análisis de esta problemática y la revisión de guías, procedimientos y métodos disponibles las empresas puedan focalizar mejor sus esfuerzos de gestión del desarrollo local y optimizar los resultados de su inversión social.

Se debe profundizar el estudio de la problemática en el ámbito de las inversiones sociales que realiza el sector minero en el país mediante la realización de foros, conferencias o debates nacionales en los que puedan intervenir los actores involucrados en su conjunto, respaldados por el mundo académico en el cual hay brillantes estudiosos del desarrollo local y nacional que podrían ayudar a esclarecer las dudas y facilitar las soluciones.

También se debe implementar una guía metodológica de inversión social, lo que no supone que todas las empresas desarrollen el mismo nivel de inversiones ni iguales proyectos de manera estandarizada; se entiende que existen distintas realidades y necesidades diferentes dentro de cada comunidad o población influenciada por un proyecto u operación minera. 
En este sentido se hace necesario un ejercicio previo para establecer una línea de base en cada experiencia para determinar exactamente lo que se necesita y lo que se debe desarrollar. En ningún caso debe esperarse que las empresas respondan de manera estandarizada a las demandas y los requerimientos de la población.

\section{Referencias bibliográficas}

BANCO CENTRAL DE RESERVA DEL PERÚ (BCRP). 2007. Reporte de inflación. Lima: BCRP (mayo).

COMPAÑÍA DE MINAS BUENAVENTURA. 2006. Balance 2006 del PRA Huancavelica. Cía. de Minas Buenaventura.

FUERTES ANAYA, Aldo. 2007. Buen gobierno corporativo. Una visión desde la sostenibilidad empresarial. XII Simposio Internacional de RSE Perú 2021. Lima.

INSTITUTO DE INGENIEROS DE MINAS DEL PERÚ (IIMP). 2007a. Aporte social y económico de la minería en el Perú: año 2006. Lima: IIMP.

2007b. Encuesta nacional a empresas mineras. Lima: IIMP.

LA ROSA, Juan Carlos. 2007. Comités de desarrollo comunal Codecos: empoderamiento para el desarrollo comunitario. Ponencia del I Congreso Internacional de Responsabilidad Social en Minería (Resmine) presentada por el alcalde de la Municipalidad Distrital de Pataz, La Libertad. Lima: Resmine.

PERÚ. MINISTERIO DE ECONOMÍA Y FINANZAS (MEF). 2007. Marco macroeconómico multianual 2008-2010. Lima: MEF.

PERÚ. PROINVERSIÓN (Agencia de Promoción de la Inversión Privada). 2005. Las
Bambas, un modelo de desarrollo sostenible. Lima: Proinversión.

PERÚ. SOCIEDAD NACIONAL DE MINERÍA, PETRÓLEO Y ENERGÍA (SNMPE). 2007. Programa minero de solidaridad con el pueblo. Folleto informativo. Lima: SNMPE. <www.snmpe.org.pe>.

PROGRAMA DE LAS NACIONES UNIDAS PARA EL DESARROLLO (PNUD). 2005. Observatorio del Desarrollo Humano. N. ${ }^{\circ}$ 6. Lima: PNUD.

QUIJANDRÍA, Gonzalo. 2007. La responsabilidad social para Antamina. Ponencia del gerente de Asuntos Corporativos de la Compañía Minera Antamina en el Foro Minería, Conservación del Medio y Comunidades: Equilibrio Alcanzable. Lima.

RÍOS QUINTEROS, Lucio. 2007. Minería, responsabilidad social y ambiental. Realidad, retos y compromisos. Ponencia presentada al Foro Nacional Minería, Responsabilidad Social y Ambiental. Realidad, Retos y Compromisos. Lima: Instituto de Seguridad Minera (ISEM).

VARGAS LÚCAR, Rosario. 2007. Participación para el empoderamiento comunitario. Ponencia presentada al I Congreso Internacional de Responsabilidad Social en Minería (Resmine). Lima: Resmine. 